\title{
Gut Microbiota, Obesity and Metabolic Dysfunction
}

\author{
Anna Meiliana ${ }^{1,2 *}$ and Andi Wijaya ${ }^{1,2 *}$
}

\begin{abstract}
${ }^{1}$ Post Graduate Program in Clinical Biochemistry, Hasanuddin University, Jl. Perintis Kemerdekaan Km.10. Makassar, Indonesia ${ }^{2}$ Prodia Clinical Laboratory, Jl. Cisangkuy No.2, Bandung, Indonesia

*Correspondence: anna_m@prodia.co.id
\end{abstract}

\section{Abstract}

B

ACKGROUND: The prevalence of obesity and related disorders such as metabolic syndrome and diabetes has vastly increased throughout the world. Recent insights have generated an entirely new perspective suggesting that our microbiota might be involved in the development of these disorders. This represents an area of scientific need, opportunity and challenge. The insights gleaned should help to address several pressing global health problems.

CONTENT: Our bowels have two major roles: the digestion and absorption of nutrients and the maintenance of a barrier against the external environment. They fulfill these functions in the context of, and with the help from, tens of trillions of resident microbes, known as the gut microbiota. Studies have demonstrated that obesity and metabolic syndrome may be associated with profound microbiotal changes, and the induction of a metabolic syndrome phenotype through fecal transplants corroborates the important role of the microbiota in this disease. Dietary composition and caloric intake appear to swiftly regulate intestinal microbial composition and function.

SUMMARY: The interaction of the intestinal microbial world with its host, and its mutual regulation, will become one of the important topics of biomedical research and will provide us with further insights at the interface of microbiota, metabolism, metabolic syndrome, and obesity. A better understanding of the interaction between certain diets and the human gut microbiome should help to develop new guidelines for feeding humans at various time points in their life, help to improve global human health, and establish ways to prevent or treat various food-related diseases.

KEYWORDS: Gut Microbiota, Obesity, Metabolic Syndrome, Type 2 Diabetes.

Indones Biomed J 2011; 3 (3): 150-167

\section{Introduction}

Along with the increasing worldwide incidence of obesityassociated disorders, researches have recently unraveled important pathways reciprocally connecting metabolism with the immune system. The development of obesity is a complex process involving genetic susceptibility and environmental factors, which both remain only partially understood. In such instances, gut microbiota is being increasingly recognized as an important factor connecting genes, environment, and immune system (1).

The human intestine harbors an enormously complex, diverse, and vast microbial community, referred to as gut microflora or microbiota (2-5). The human gut microbiota is estimated to consist of at least $10^{14}$ bacteria and archaea, composed of approximately 1,100 prevalent species, with approximately 160 such species per individual.

The genome size of this microbial organ, collectively named microbiome, exceeds the size of the human 
nuclear genome by two orders of magnitude and provides important biological and metabolic functions that cannot be performed by researchers. Genomic and environmental factors at the basis of mutual host-microbiota interactions have been intensely investigated with metagenomic and metabolomic approaches in the last 5 years (1).

Important studies on the relationship of the intestinal microbial flora with obesity have uncovered profound changes in the composition and metabolic function of the gut microbiota in obese individuals (6-9), which appear to enable the "obese microbiota" to ex tract more energy from the diet (10). Moreover, these studies have demonstrated that the gut microbiota interacts with host epithelial cells to indirectly control energy expenditure and storage (6).

Gut microbiota play an important role in conditions such as obesity, diabetes, metabolic syndrome and nonalcoholic fatty liver disease. Regulation of energy uptake from the gut, by digesting otherwise indigestible common polysaccharides in our diet, production or activation of signaling molecules involved in host metabolism, modification of gut permeability, the release of gut hormones and inflammation, are among the mechanisms by which gut microbiota may influence the host cardiometabolic phenotype.

Modification of the gut microbiota composition and/or its biochemicalcapacity by specific dietary or pharmacological interventions may favorably affect host metabolism (11). The recently initiated international Human Microbiome Project (HMP) aims to better understand the structure and function of the microbial communities that inhabit the gut and other niches within the human body and their role in health and disease (8). Insights obtained from the HMP will aid to develop evidence-based prebiotic and/or pro-biotic interventions that will enable manipulation of the gut-microbiota to ultimately improve and/or prevent disease states (11).

\section{The Intestinal Microbiome}

The adult human body typically comprises ten times more microbial cells than human cells, due largely to the extremely high density of microbes found in the human intestinal tract (typically $10^{11}-10^{12}$ microbes $/ \mathrm{mL}$ of luminal content). This microbial ecosystem serves numerous important functions for its human host, including protection against pathogens, nutrient processing, stimulation of angiogenesis, and regulation of host fat storage $(6,7,12-$ 16).
The GI tract can be regarded as a very complex ecosystem because it does not involve solely eukaryotic tissues like in other organs, but involves an interplay between food, host cells and microbes $(17,18)$. The combined biochemical capacity of the microbiota has been called a "forgotten organ," (19) mediating diverse beneficial roles including vitamin synthesis, bile salt metabolism, and xenobiotic degradation (20), but likely the collective biochemical output, the "metabolome," is involved in additional processes. "Metabolomics" is another system-based approach of high-throughput analysis of complex biological samples that has great promise in linking functional consequences to ecological changes in the microbiotal community (4).

Using metagenomic techniques to describe altered community composition (a reduction in Bacteroidetes and an increase in Firmicutes) in genetically obese (ob/ ob) mice, Turnbaugh et al. showed this microbiota had an augmented ability to liberate an additional energy source (short-chain fatty acids [SCFAs]) for host uptake (10). These population changes were correlated with observations in lean and obese humans (12) and suggest that the microbiota of an obese person is more efficient at extracting energy from the diet than that of a lean individual (20).

The normal microbiota thrives in a largely anaerobic luminal environment, generating its own energy through the fermentation of dietary complex carbohydrates. Complex carbohydrates (starches) are poorly digested by the human digestive system and require the microbiota for breakdown via fermentation. In the human gut, the end products of fermentation are a spectrum of organic acids, including SCFAs such as butyrate, succinate, and propionate as well as other terminal products such as lactate $(15,21)$. SCFAs are an important energy source for the colonic epithelium and the host, providing for an estimated $5 \%-15 \%$ of human energy requirements (22). The organisms most efficient at producing SCFAs (the microbes possessing the enzymatic capacity to ferment these substrates) are Firmicutes such as Clostridium species and Bifidobacterium species, which are enriched in the microbiota of obese mice and humans (10). Thus, SCFAs are bacterial products and well-known host energy sources that provide a link from community-level changes in microbiotal composition and their encoded metabolic machinery to a human phenotype.

SCFAs also show an intriguing ability to influence various aspects of gut physiology beyond functioning solely as a crude caloric source $(23,24)$. For example, butyrate and other SCFAs have well-known differentiating and growth-promoting activities in vitro and in vivo, a 
biological effect ascribed to histone deacetylase activity. SCFAs have also been noted to have immunomodulatory effects, suppressing inflammatory cytokine secretion in cultured epithelial cells and ameliorating model colitis in mice, suggesting these molecules contribute to the ability of the mucosa to tolerate the presence of vast quantities of living microorganisms and associated MAMPs. Butyrate can induce epithelial production of ROS and subsequent redox-dependent signaling effects including NF- $x$ B suppression (25). Furthermore, luminal instillation of butyrate has been shown to be a promising experimental therapy in human ulcerative colitis and related inflammatory disorders $(23,26)$. SCFAs appear to be a class of effector molecule, produced preferentially by one subset of the microbiotal community.

The assembly of the human gut microbiota begins during birth with colonization by microbes from the environment. In the first few hours of life, the mother's vaginal and fecal microbiomes are usually the most important source of inoculum $(27,28)$. During the initial few months of a milk diet, bacteria such as Bifidobacteria, highly adapted to process milk oligosaccharides, can be abundant (29). The introduction of solid foods heralds a shift toward bacterial consortia characteristic of the adult microbiota (30).

Interpersonal variation in gut microbial diversity is greater between infants than between adults, and furthermore, the infant microbiome displays more interpersonal variability in functional gene content than the adult microbiome (31). The large functional and phylogenetic variation observed between infant gut microbiomes may be due to random colonization events, differences in immune responses to the colonizing microbes, changes in host behavior, or other aspects of host lifestyle $(30,32)$. How each of these factors contributes to shaping the infant microbiome remains unclear (33).

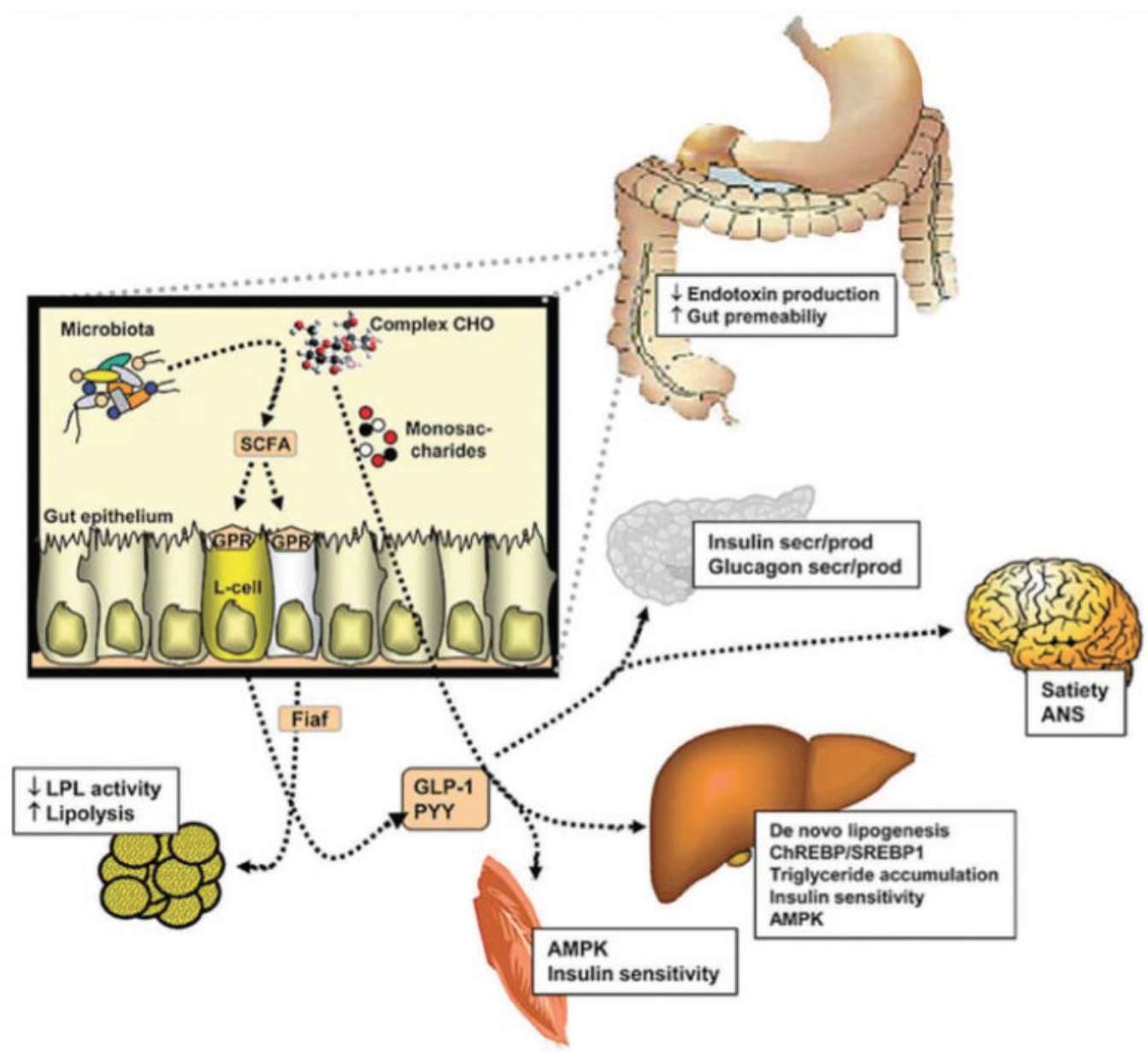

Figure 1. Mechanisms proposed by which gut microbiota may influence the host cardiometabolic phenotype (Adapted with permission from Diamant M, John Wiley \& Sons Inc. 2010). 
The interrelationships between our diets and the structure and operations of our gut microbial communities are poorly understood. The composition of microbial communities is generally stable within each individual (34). Past studies of the gut microbiota emphasized the huge impact of nutrition (35), which is likely to outweigh that of the host genotype (36). A controlled-feeding study of 10 subjects showed that microbiome composition changed detectably within 24 hours of initiating a high-fat/lowfiber or low-fat/high-fiber diet, but that enterotype identity remained stable during the 10-day study. Thus, alternative enterotype states are associated with long-term diet (37).

Defining the interrelationship between diet and the structure and operations of the human gut microbiome is key to advancing our understanding of the nutritional value of food, for creating new guidelines for feeding humans at various stages of their life span, for improving global human health, and for developing new ways to manipulate the properties of the microbiota so as to prevent or treat various diseases (38).

Before the Human Genome Project was completed, some researchers predicted that $\sim 100,000$ genes would be found. So, many were surprised and perhaps humbled by the announcement that the human genome contains only $\sim 20,000$ protein-coding genes, not much different from the fruitfly genome. However, if the view of what constitutes a human is extended, then it is clear that 100,000 genes is probably an under- estimate. The microorganisms that live inside and on humans (known as the microbiota) are estimated to outnumber human somatic and germ cells by a factor of ten. Together, the genomes of these microbial symbionts (collectively defined as the microbiome) provide traits that humans did not need to evolve on their own. If humans are thought of as a composite of microbial and human cells, the human genetic landscape as an aggregate of the genes in the human genome and the microbiome, and human metabolic features as a blend of human and microbial traits, then the picture that emerges is one of a human 'supra-organism' (7).

TTo understand the range of human genetic and physiological diversity, the microbiome and the factors that influence the distribution and evolution of the constituent microorganisms must be characterized. This is one of the main goals of the Human Microbiome Project (HMP). The outcome might also provide perspective on contemporary human evolution: that is, on whether and how rapidly advancing technology, and the resultant transformation of human lifestyles and the biosphere, influences the 'micro-evolution' of humans and thereby health and predisposition to various diseases $(7,39)$.

\section{Maintenance of Intestinal Homeostatis}

The human intestine harbors enormous amounts of bacteria that have an essential role in host metabolism, but how this mutualistic balance is maintained is unclear. The current understanding has focused on the concept that bacteria continuously interact with the intestinal immune system in a balanced proinflammatory and tolerogenic way. The discovery of a protective inner mucus layer in the colon that separates bacteria from the epithelium has broadened this view (40).

The intestine contains nutrients that can be used by the bacteria, and the body temperature is optimal for the microbes. With such favorable conditions, it is remarkable that the host is not taken over by the fastgrowing bacteria. To handle this, the host has a number of mechanisms including the adaptive immune system and its production and secretion of secretory $\operatorname{IgA}(41,42)$. Even more important are components belonging to the innate immune system, some of which, like lysozyme and the antibacterial peptides, have antibacterial properties $(43,44)$. The majority of the intestinal immune system is active in the small intestine, which is also more exposed to the intestinal bacteria $(43,45)$. Passage through the small intestine is relatively fast $(3-5 \mathrm{~h})$, which gives limited time for bacteria to increase in number. This is in contrast to the colon, where bacteria reside for a much longer time. In colon, the high number of commensal bacteria live in symbiosis with their host as they help to extract energy by digesting indigestible glycoconjugates and contribute vitamins to the host (46).

An enormous surface area of mucosal epithelial cells in the gastrointestinal tract is potentially exposed to enteric microorganisms. The mucosal epithelium has highly specialized functions throughout the gastrointestinal tract to allow ingested food to be digested, absorbed and processed for excretion. These processes must coexist with the need to provide a barrier both to the commensal microorganisms that ferment undigested food material in the lumen of the intestine and to potential viral, bacterial and eukaryotic pathogens. The mutually beneficial relationship between the commensal microorganisms and the host is a delicate balance that is maintained by appropriate host barrier function and by specific adaptations of the microorganisms (40).

In order to protect the mucosa, the host produces a thick, complex layer of mucus that covers the 
gastrointestinal tract in the stomach, the small intestine and the large intestine. The mucus is organized in two layers: an inner, stratified mucus layer that is firmly adherent to the epithelial cells and approximately $50 \mu \mathrm{m}$ thick; and an outer, nonattached layer that is usually approximately 100 $\mu \mathrm{m}$ thick as measured in mouse. These mucus layers are organized around the highly glycosylated MUC2 mucin, forming a large, net-like polymer that is secreted by the goblet cells. The inner mucus layer is dense and does not allow bacteria to penetrate, thus keeping the epithelial cell surface free from bacteria. The inner mucus layer is converted into the outer layer, which is the habitat of the commensal flora. The outer mucus layer has an expanded volume due to proteolytic activities provided by the host but probably also caused by commensal bacterial proteases and glycosidases. The numerous O-glycans on the MUC2 mucin not only serve as nutrients for the bacteria but also as attachment sites and, as such, probably contribute to the selection of the species-specific colon flora. This observation that normal human individuals carry a uniform MUC2 mucin glycan array in colon may indicate such a specific selection $(40,47,48)$.

Gastrointestinal epithelial cells are tightly linked via intracellular junctions that form a contiguous barrier which is resistant to microbial passage. Thus, there are three levels to the barrier to infection: secreted mucus, the apical glycocalyx and epithelial tight junctions (47) The secreted (gelforming) mucin glycoproteins that form the major macromolecular constituents of mucus are produced by specialized mucus or goblet cells that are found throughout the gastrointestinal tract. The other major secretory cells within the gastrointestinal tract are the Paneth cells, which are primarily found adjacent to stem cells deep in the crypts of the small intestine. Paneth cells are identified by their characteristic intracellular granules containing a range of antimicrobial molecules that are secreted into the mucus to ensure sterility of the stem cell niche (49).

Goblet cells secrete several other proteins into the mucus in addition to mucins, such as trefoil peptides. Trefoil peptides have been implicated in noncovalent binding to mucins (50-52) and appear to be capable of altering the biophysical and protective properties of the mucus $(53,54)$ Some individual trefoil peptides are tightly coexpressed with specific secreted gel-forming mucins.

The mucus gel provides a matrix for the retention of antimicrobial molecules in the mucosal environment; these molecules are produced throughout the gastrointestinal tract, primarily by Paneth cells, and include $\alpha$ defensins, cathlecidins, lysozymes, angiogenin 4 , secretory phospholipase A2, lipopolysaccharide-binding protein, collectins, histatins, and lectins such as REGIII $\alpha$ (also known as HIP and PAP) and REGIII $\gamma(49,55,56)$. Although these molecules have a wide variety of structures, many are microbicidal lectins or small, amphipathic, cationic peptides, and interact with and disrupt microbial cell membranes $(57,58)$.

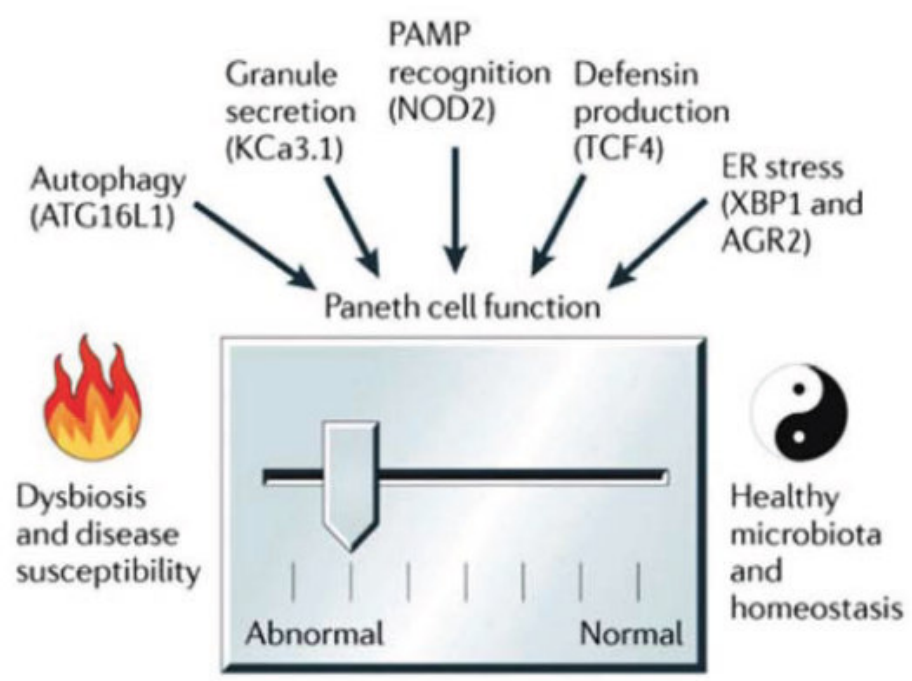

Figure 2. Paneth cell dysfunction may predispose to intestinal inflammation (Adapted with permission from Bevin CL, et al, Nature Publishing Group 2011). 
Paneth cells deliver a potent cocktail of antimicrobial peptides into the intestinal lumen, and this cocktail moulds the composition of the colonizing microbiota (60) and protects the host from enteric pathogens $(61,62)$. When functioning optimally, Paneth cells contribute to homeostasis. Several genetic susceptibility factors for human inflammatory bowel disease, and Crohn's disease in particular, may have their phenotypic underpinnings in Paneth cell dysfunction. These include ATG16L1 (63), KCNN4 (encoding the calcium-activated potassium channel KCa3.1 (also known as SK4)) (64), NOD2 $(65,66)$ TCF4 (T cell-specific transcription factor 4; also known as TCF7L2) (67) XBP1 (X-box-binding protein 1 gene) (68) and AGR2 (69). These susceptibility factors encode proteins that are involved in autophagy, granule secretion, pathogen-associated molecular pattern (PAMP) recognition, defensin production and endoplasmic reticulum (ER) stress. Mouse models also support the key functions of each of these implicated pathways in gut immune homeostasis $(68,70-75)$.

Building and maintaining a homeostatic relationship between a host and its colonizing microbiota entails ongoing complex interactions between the host and the microorganisms. The mucosal immune system, including epithelial cells, plays an essential part in negotiating this equilibrium. Paneth cells (specialized cells in the epithelium of the small intestine) are an important source of antimicrobial peptides in the intestine (59).

The separation of bacteria and epithelium has emerged as a new concept underlying host-microbiota homeostasis in the small intestine and colon, although by different mechanisms. The different ways these organs solve the challenge of bacterial colonization must have evolved to meet the different physiological needs $(39,76)$.

\section{Nutrition, Gut Microbiome and The Immune System}

Although microbes have been classically viewed as pathogens, it is now well established that the majority of host-bacterial interactions are symbiotic. During development and into adulthood, gut bacteria shape the tissues, cells and molecular profile of our gastrointestinal immune system. This partnership, forged over many millennia of coevolution, is based on a molecular exchange involving bacterial signals that are recognized by host receptors to mediate beneficial outcomes for both microbe and man. Understanding the molecular mechanisms which mediate symbiosis between commensal bacteria and humans may redefine how we view the evolution of adaptive immunity, and as a result, the way we approach treating numerous immunologic disorders (77)

Intestinal homeostasis depends on complex interactions between the microbiota, the intestinal epithelium and the host immune system. Diverse regulatory mechanisms cooperate to maintain intestinal homeostasis, and a breakdown in these pathways may precipitate the chronic inflammatory pathology found in inflammatory bowel disease. The intestinal epithelium represents a huge surface area of approximately $100 \mathrm{~m}^{2}$ that is lined by a single layer of columnar intestinal epithelian cells (IECs), which form a stout physical barrier. IECs, however, form much more than a simple physical barrier that processes and absorbs dietary nutrients. They perform several other functions that are crucial for intestinal homeostasis (78). These include secretion of compounds that influence microbial colonization, sampling of the intestinal microenvironment, sensing of both beneficial and harmful microbes, and induction and modulation of immune responses. To fulfill such diverse functions, the intestinal epithelium has unique anatomical and cellular adaptations, and IECs comprise several specialized cell types with distinct functions $(78,79)$.

Many recent reviews have described the known interactions between the innate and adaptive immune system and the tens of trillions of microbes that live in our gastrointestinal tracts. Increasing evidence shows that the nutritional value of food is influenced in part by the structure and operations of a consumer's gut microbial community, and that food, in turn, shapes the microbiota and its vast collection of microbial genes (the gut microbiome) $(80,81)$ Therefore, to define the nutritional value of foods and our nutritional status better, we need to know more about our microbial differences and their origins, including how our lifestyles influence the assembly of gut microbial communities in children, and about the transmission of these communities within and across generations of a kinship (82). We are learning how our gut microbial communities and immune systems co-evolve during our lifespans, and how components of the microbiota affect the immune system.

We believe that the 'marriage' of two approaches - one involving culture- independent (metagenomic) methods for describing the gut microbiota or microbiome and the other involving gnotobiotics (the rearing of animals under germ-free conditions, with or without subsequent exposure during postnatal life or adulthood to a microbial species or species consortium) - is a potentially powerful way to address several questions about the relationships 
between diet, nutritional status, the assembly and dynamic operations of gut microbial communities, and the nature of the interkingdom communications between the gut microbiota and the host (including host-microbial cometabolism, and the co-evolution of the immune system) $(81,83,84)$.

We know from metagenomic studies of the human gut microbiota and microbiome that early postnatal environmental exposures have an important role in determining the overall phylogenetic structure of an adult human gut microbiota. The assembly of the microbiota towards an adult configuration occurs during the first three years of life (33), and features of the organismal and gene content of gut communities are shared among family members and transmitted across generations of a kinship (82). We also know that dietary habits influence the structure of the human genome. Together, these observations lead to the notion that systematic changes in overall dietary consumption patterns across a population might lead to changes in the microbiome, with consequences for host nutritional status and immune responses (85).

Short-chain fatty acids (SCFAs) provide one of the clearest examples of how nutrient processing by the microbiota and host diet combine to shape immune responses. SCFAs are end products of the microbial fermentation of macronutrients, most notably plant polysaccharides that cannot be digested by humans alone because our genomes do not encode the large repertoire of glycoside hydrolases and polysaccharide lyases needed to cleave the varied glycosidic linkages present in these glycans (86). These missing enzymes are provided by the microbiome. The luminal concentration of intestinal SCFAs can be modified by the amount of fibre in the diet, which affects the composition of the microbiota (87). In addition to acting as an energy source for the host, SCFAs exert notable effects on host immune responses. Low levels of butyrate modify the cytokine production profile of TH cells (88) and promote intestinal epithelial barrier integrity (89), which in turn can help to limit the exposure of the mucosal immune system to luminal microbes and prevent aberrant inflammatory responses. Production of another SCFA, acetate, by the microbiota promotes the resolution of intestinal inflammation by the G-proteincoupled receptor GPR43 (90),

If nutrients and derived metabolites reflect the functional activity of the microbiota, sensors of nutrient and metabolite availability can be considered akin to microbeassociated molecular patterns (MAMPs) that convey information about microbes to the host. Several families of innate receptors are involved in the recognition of MAMPs: these include Toll-like receptors (TLRs), inflammasomes,
C-type lectins such as dectin-1, and RNA-sensing RIGlike helicases such as RIG-I and MDA5. TLR4 can sense the presence of free fatty acids (91), whereas ATP is an important activator of the inflammasome (92). Several other immune-cell-associated sensors couple information about the local nutrient or metabolite environment to the coordination of local immune responses. Examples are the serine/threonine kinase mammalian target of rapamycin (mTOR) (93), double-stranded RNA-activated protein kinase (PKR) (94), the aryl hydrocarbon receptor (AHR) (95), and various nuclear hormone receptors such as the liver-X-receptor and the peroxisome-proliferatoractivated receptors (PPAR- $\alpha$, PPAR- $\beta$ and PPAR- $\gamma$ ) (96). The mTOR pathway is an example of how energy availability affects immune responses. mTOR is activated by phosphatidylinositol-3-OH kinase and the serine/ threonine kinase AKT, and is inhibited by AMP-activated protein kinase, which is a sensor of cellular energy resources.

PKR couples the presence of free fatty acids to immune activation, and has been implicated in the pathogenesis of obesity in mice fed a high-fat diet, including their development of immunoinflammatory and insulin resistant phenotypes (94). AHR is activated by several agonists, including kynurenine - a product of tryptophan metabolism by indoleamine-2,3-dioxygenase $(97,98)$. AHR modulates the differentiation of dendritic cells (99) and promotes TH17-cell and Treg-cell differentiation and effector activity $(100,101)$.

The intestinal microbiota can synthesize several vitamins involved in myriad aspects of microbial and host metabolism, including cobalamin (vitamin B12), pyridoxal phosphate (the active form of vitamin B6), which is involved in several enzymatic interconversions in amino-acid metabolism, pantothenic acid (vitamin B5), niacin (vitamin B3), biotin, tetrahydrofolate and vitamin $\mathrm{K}$. In addition to vitamin B12, gut microbes produce a range of related molecules (corrinoids) with altered 'lower ligands', including analogues such as methyladenine and $\beta$-cresol. More than $80 \%$ of non-absorbed dietary vitamin B12 is converted to these alternative corrinoids $(102,103)$.

Folate and cobalamin produced by the gut microbiota could affect host DNA methylation patterns, whereas acetate produced by the microbial fermentation of polysaccharides could modify chromatin structure and gene transcription by histone acetylation. Thus, the inheritance of a mammalian genotype and intergenerational transmission of a microbiome - together with a complex dynamic in which the microbiome is viewed both as an epigenome and a modifier of the host epigenome during 
the postnatal period when host, host diet and microbial community co-evolve - could together shape human physiological phenotypes that are manifested during childhood or later in life (85).

Obesity, metabolic syndrome and diabetes illustrate the role that the diet-microbiota-immune axis has in shaping human systems biology. Although the marked increase in obesity worldwide can be linked to an evergrowing trend towards excessive caloric intake, the microbiota has also been implicated in obesity (85).

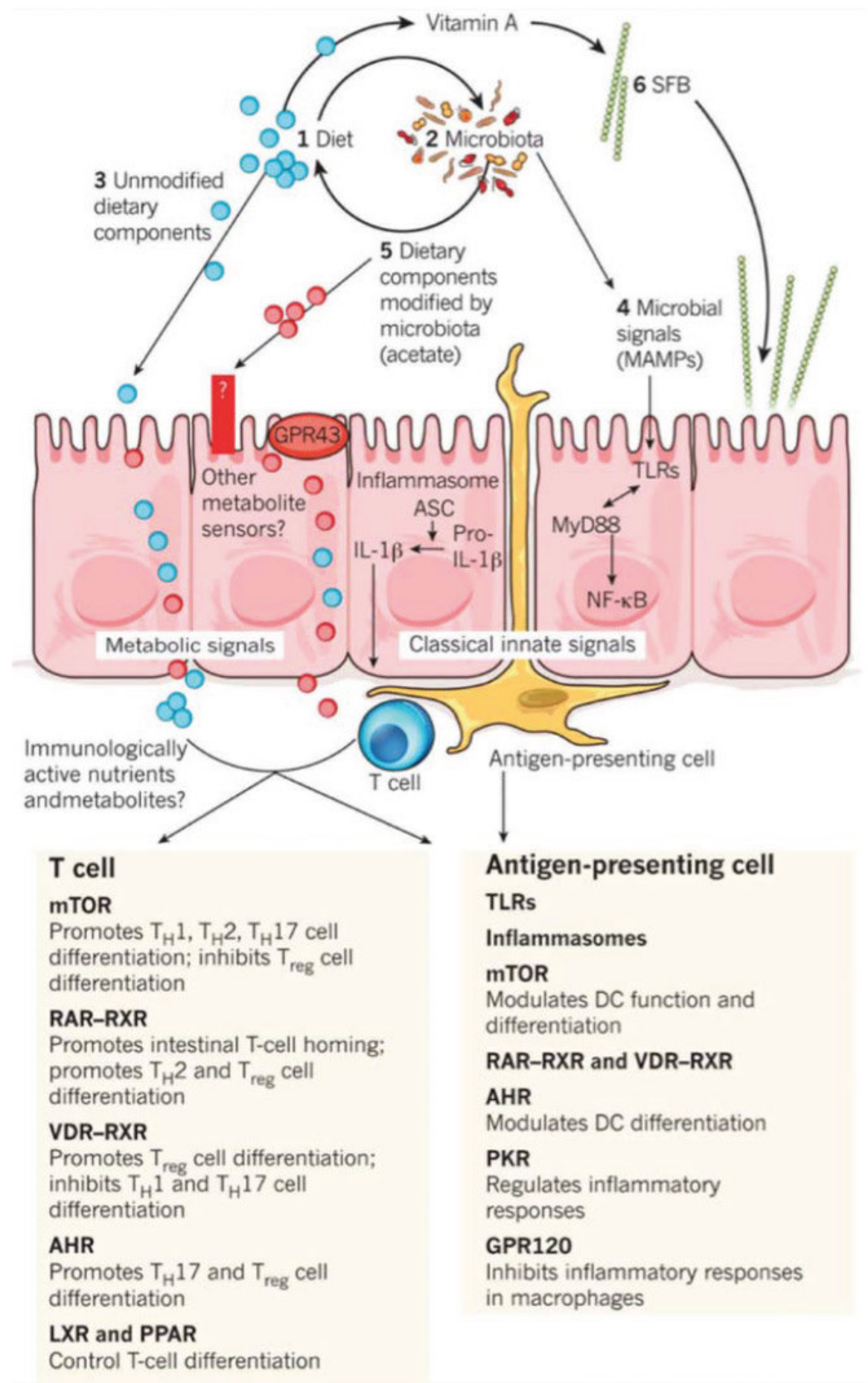

Figure 3. PMetabolite sensors that help to coordinate immune responses (Adapted with permission from Kau Al, Nature Publishing Group 2011). 


\section{Gut Microbiota in the Regulation of Energy Homeostasis and Fat Storage}

microbiota can directly (via afferent nerve terminals) or indirectly (via signalling peptides) modulate gut motility, alter secretion of gut hormones, including GLP-1, GLP-2 and PYY, gut permeability and immune function. These alterations may additionally influence host metabolism and pro-inflammatory state (11).

Energy balance is an equilibrium between the amount of energy taken in as food and the amount expended during resting metabolism, as well as the thermic effect of food, physical activity, and loss in the faeces and urine (10). 'Our' microbial genomes (the microbiome) encode metabolic capacities that we have not had to evolve wholly on our own $(46,104)$, but remain largely unexplored. These include degradation of otherwise indigestible components of our diet (105), and therefore may have an impact on our energy balance.

Comparisons of the distal gut microbiota of genetically obese mice and their lean littermates, as well as those of obese and lean human volunteers have revealed that obesity is associated with changes in the relative abundance of the two dominant bacterial divisions, the Bacteroidetes and the Firmicutes (10). This change involves several linked mechanisms: microbial fermentation of dietary polysaccharides that cannot be digested by the host; subsequent intestinal absorption of monosaccharides and short-chain fatty acids; their conversion to more complex lipids in the liver; and microbial regulation of host genes that promote deposition of the lipids in adipocytes (6). These findings have led us to propose that the microbiota of obese individuals may be more efficient at extracting energy from a given diet than the microbiota of lean individuals $(6,46)$.

LPL is a key regulator of fatty acid release from triglyceride-rich lipoproteins in muscle, heart, and fat (106). Increased adipocyte LPL activity leads to increased cellular uptake of fatty acids and adipocyte triglyceride accumulation. In white fat, LPL is regulated posttranscriptionally by nutritional status: fasting reduces and refeeding increases enzyme activity (107). Fasting-induced adipocyte factor (Fiaf), a member of the angiopoietin-like family of proteins, is selectively suppressed in the intestinal epithelium of normal mice by conventionalization. Analysis of germ-free (GF) and conventionalized, normal and Fiaf knockout mice established that Fiaf is a circulating lipoprotein lipase inhibitor and that its suppression is essential for the microbiota-induced deposition of triglycerides in adipocytes (6).

Recent studies suggest that the gut microbiota is an important environmental factor that affects energy harvest from the diet and energy storage in the host (6). Gut

\section{Gut Microbiota, Obesity, Metabolic Syndrome, and Diabetes}

Although the root cause of obesity is excess caloric intake compared with expenditure, differences in gut microbial ecology between humans may be an important factor affecting energy homeostasis; i.e., individuals predisposed to obesity may have gut microbial communities that promote more efficient extraction and/or storage of energy from a given diet, compared with these communities in lean individuals (7).

New molecular, culture-independent techniques that are based on microbial DNA sequencing have profoundly transformed our ability to study microbial communities $(108,109)$. These techniques have demonstrated that the mammalian gut microbiota belongs predominantly to four bacterial phyla: the Gram-negative Bacteroidetes and Proteobacteria and the Gram-positive Actinobacteria and Firmicutes. Initial evidence for an altered microflora associated with obesity revealed that ob/ob mice exhibit a major reduction in the abundance of Bacteroidetes and a proportional increase in Firmicutes (7). Feeding of a high-fat/high- polysaccharide diet to genetically wild-type rodents led to similar microbial changes. Confounding factors affecting microbial composition and function may include diet per se, the use of antibiotics, which substantially reduce bacterial diversity (110), and possibly effects related to the genetic background of animal models (111). Consistent with animal models, Ley et al. observed analogous differences with an increase in the ratio of Firmicutes/Bacteroidetes in the distal gut microbiota in human obesity (12).

Several lines of evidence suggest that dietary factors might profoundly influence microbiotal composition. Studies in resistin-like molecule $\beta$-knockout mice, which are resistant to diet-induced obesity, revealed that dietary factors are the key determinant of microbial composition, and indeed appear more relevant than obe- sity per se (112). In this study, switching to a high-fat diet resulted in a decrease in Bacteroidetes, whereas the numbers of Firmicutes and Proteobacteria increased. Importantly, 
this was observed in both the presence and absence of obesity, clearly suggesting that diet must be considered as a confounding factor affecting microbial composition (113).

The genetic background of our microbiota might determine how certain dietary factors are handled. Genetic and functional differences between Bacteroides spp. are predictive how these bacteria utilize fructans, a class of fructose-based polysaccharides (114). Undoubtedly, diet critically affects the gut microbiome, changes occur very rapidly, and adiposity might be transferable by fecal transplantation.

Recent data have shown that these metabolic disorders, obesity and type 2 diabetes, are characterised by low-grade inflammation of unknown molecular origin $(115,116)$; therefore, it is of the utmost importance to identify the link between inflammation and adipose tissue metabolism, and plasticity. Emerging data have implicated gut microbiota $(7,10,117-120)$ and the endocannabinoid (eCB) system $(121,122)$ as modulators of obesity and energy homeostasis. Obesity is characterised by the massive expansion of adipose tissues and is associated with inflammation (123). It is possible that both this expansion and the associated inflammation are controlled by microbiota and lipopolysaccharide (LPS) $(117,119)$, a cell wall component of Gram-negative bacteria that is among the most potent inducers of inflammation.

The endocannabinoid system has also been shown to potentially mediate the influence of microbiota on gut permeability. Studies involving specific antagonists and agonists demonstrated that the endocannabinoid system controls not only gut permeability but also plasma LPS levels and adipogenesis (124). Endocannabinoids increase mRNA expression of the tight junction protein occludin-1 and decrease expression of claudin-1, further supporting a potential role in the regulation of intestinal permeability (125). Thus gut microbiota and the eCB system control gut permeability and adipogenesis through an LPSdependent mechanism under physiological and obesityrelated conditions (124).

The connection between gut microbiota and energy homeostasis and inflammation and its role in the pathogenesis of obesity-related disorders are increasingly recognized. Animals models of obesity connect an altered microbiota composition to the development of obesity, insulin resistance, and diabetes in the host through several mechanisms: increased energy harvest from the diet, altered fatty acid metabolism and composition in adipose tissue and liver, modulation of gut peptide YY and glucagon-like peptide (GLP)-1 secretion, activation of the lipopolysaccharide toll-like receptor- 4 axis, and modulation of intestinal barrier integrity by GLP-2. Instrumental for gut microbiota manipulation is the understanding of mechanisms regulating gut microbiota composition (1).

Following encouraging results in animals, several short-term randomized controlled trials showed the benefit of prebiotics and probiotics on insulin sensitivity, inflammatory markers, postprandial incretins, and glucose tolerance. Future research is needed to unravel the hormonal, immunomodulatory, and metabolic mechanisms underlying microbe-microbe and microbiotahost interactions and the specific genes that determine the health benefit derived from probiotics (1).

The dynamic linkage between adiposity and gut microbial ecology described here, together with our results from mice, indicates that manipulation of gut microbial communities could be another approach in the treatment of obesity (12). Metabolic syndrome is thought to develop through the interaction of various genetic and environmental factors. A complex and still poorly characterized interaction between the intestinal microbiota and the innate immune system may be involved in metabolic dysfunction (126). Metabolic syndrome, diabetes, and obesity are characterized by lowgrade inflammation, and adipokines play a central role (127). Ob/ob mice treated with antibiotics (norfloxacin and ampicillin) exhibit changes in the microbiota and an improvement in insulin resistance, fasting glycemia, and glucose tolerance compared with control ob/ob mice (128), along with a reduction in systemic "metabolic" endotoxemia and inflammatory parameters (119).

Gut microbiota are likely indispensable for obesity development, as GF animals are resistant to high-fat diet (HFD)-induced obesity, indicating that high-calorie food alone is not sufficient to induce obesity and insulin resistance (129). It has been shown that HFDs disrupt gut microbiota in two ways, diminishing levels of gut barrierprotecting bifidobacteria and promoting the growth of endotoxin producers (118). These changes eventually result in higher levels of lipopolysaccharide (LPS) in the host blood, causing inflammation, and consequently, obesity and insulin resistance $(117,118)$. Although specific endotoxin producers remain to be identified, these observations highlight the important mediating role of gut microbiota in diet-induced MS (130).

A recent report revealed a profound effect of the innate immune receptor, the pattern recognition receptor Tlr5, on structural microbial composition and the consequences for the pathogenesis of metabolic syndrome (131). Transfer of disease phenotypes via the microbiota has also been reported for colitis (132) and obesity (10). The fascinating 
triangular relationship between the microbiota, the innate immune system, and metabolic function allows for a completely new perspective on related diseases. Besides immune and inflammatory mechanisms, other pathways may be involved in the link between gut microbiota and metabolic syndrome. Our microbiota produces enzymes that degrade ingested polysaccharides, thereby promoting the absorption of nutrients (especially carbohydrates), resulting in increased liver lipogenesis, hepatic insulin resistance, and hyperinsulinemia (113).

There is ample evidence that diabetes mellitus affects gastrointestinal morphology and function. Conversely, the gut affects diabetes: several recent publications provide evidence that an altered bowel function contributes to the pathogenesis of diabetes mellitus (133). Recent studies investigating the underlying mechanisms involved in disease development in diabetes point to the role of the dysregulation of the intestinal barrier. Via alterations in the intestinal permeability, intestinal barrier function becomes compromised whereby access of infectious agents and dietary antigens to mucosal immune elements is facilitated, which may eventually lead to immune reactions with damage to pancreatic beta cells and can lead to increased cytokine production with consequent insulin resistance (133).

The intestinal barrier is particularly relevant with focus on intestinal permeability (IP), immune response and intestinal microbiota. Intestinal barrier function is compromised in various gastrointestinal disorders such as inflammatory bowel disease, celiac disease, nonalcoholic steatohepatitis/non-alcoholic fatty liver disease (NASH/ NAFLD) and irritable bowel disease, but also in autoimmune and systemic diseases (134).

The structure and function of tight junctions $(134,135)$, which appear to have a principal role in regulating paracellular transport across the intestinal epithelium. In brief, the junctions between adjacent epithelial cells consist of the more luminally situated tight junctions and the basally situated adherens junctions. Tight junction proteins form fibrils that cross the membrane to interact with neighbouring cells. The fibrils between two cells consist of at least two proteins, namely occludin and members of the claudin family. These two proteins are indirectly linked with actin filaments through the intracellular scaffold proteins ZO-1, ZO-2 and ZO-3. It is thought that contraction of these cytoskeletal actin filaments regulates paracellular permeability.

An increased IP, often referred to as a 'leaky gut', has been proposed to be associated with several disorders, including intestinal and liver diseases, autoimmune disorders and also type 1 and type 2 diabetes. Although an altered intestinal barrier function can be a consequence of disease exacerbation, clinical evidence suggests that it might be a primary causative factor predisposing to disease development (134). Nevertheless, increased IP makes the host more viable and prone to immune reactions against antigens from dietary (cow milk substances like bovine insulin (136) or wheat gliadins), viral or bacterial origin. These agents can activate humoral responses and translocate to lymphoid tissue surrounding the pancreas where they may trigger autoimmune reactions against insulin producing beta cells

High-fat and high-caloric diets have been shown to favour the colonization of the intestine with Gramnegative microbiota, leading to increased plasma LPS levels (metabolic endotoxemia), whereas the quantity of Bacteroidetes spp. decreases and that of Firmicutes spp. increases (7). Increased plasma LPS levels induce production of pro-inflammatory cytokines and may lead to insulin resistance. The LPS is transported from the intestinal lumen towards the target tissue by a mechanism facilitated by chylomicrons synthesized from the intestinal epithelial cells in response to a high-fat diet (137). The LPS then binds to toll-like- 4 receptors on macrophages and triggers secretion of pro-inflammatory cytokines. Furthermore, high-fat diet strongly increases IP, probably mediated by reducing the expression of ZO-1 and occludin, favouring translocation of LPS through the intestinal wall (119).

Although these findings support a role of increased epithelial permeability, altered intestinal microbiota and sub-metabolic endotoxemia as causal factors in type 2 diabetes (133). Therefore, reinforcing intestinal barrier function may become an important objective to help prevent or counteract pathophysiological mechanisms in diabetic patients. Interventions with butyrate, prebiotics, antibiotics and GLP-2 agonists have been employed with varying success in animal studies (133).

\section{Gut Microbiota, Lipid Metabolism} and Atherosclerosis

A recent metabolomic study provides evidence that microbial metabolism of lipids in the gut yields product(s) that promote atherosclerosis. These results add another dimension-the microbiome-to the complex determinants of atherogenesis (138).

The development of cell replacement therapies usinaGut flora can significantly influence the bioavailability of dietary constituents and their metabolism in mammalian 
hosts (139). Susceptibility to obesity (109) and insulin resistance (140) are determined by the specific metabolic characteristics of gut microbiota. The ability of this unique microbial community to exert such dramatic effects on metabolism should not be surprising when one considers that nearly $99 \%$ of the genes in humans are microbial in origin (141). With the rapid evolution of metagenomic technologies, the genetic variation in intestinal microbiota and its stratification have recently been characterized, as well, with three specific enterotypes of gut flora defined and their relationships to host phenotypes (eg, body mass index) elucidated (142).

Armed with this growing knowledge of the influence of gut flora on metabolism and supportive of prior work showing that gut microbiota modulate host energy and lipid metabolism (143) through coordinated regulation of the metabolome and lipidome (145).

Wang et al. (145) outline a remarkable chain of events that links diet, intestinal bacteria and liver metabolism to the generation of a chemical that promotes the build-up of arterial plaque and cardiovascular disease (146). The authors found major differences in choline, betaine and trimethylamine $\mathrm{N}$-oxide (TMAO) - three metabolites of the ubiquitous dietary lipid phosphatidylcholine (also called lecithin). Choline is an essential nutrient (147) and lack of dietary choline can lead to non-alcoholic fattyliver disease and muscle damage. After choline is released from phosphatidylcholine by phospholipase enzymes, gut microbiota metabolize much of it into trimethylamine (TMA) - a gas that smells like rotten fish. When TMA reaches the liver, oxidizing flavin monooxygenase enzymes convert it into TMAO.

Wang and colleagues (145) demonstrated a unique cluster of three phospholipid-associated molecules that appear to promote atherosclerosis. They first performed a rigorous metabolomic analysis of the plasma of patients with known but stable atherosclerotic disease, identified three metabolites of dietary phosphatidylcholinecholinebetaine, and, trimethylamine $\mathrm{N}$-oxide (TMAO) and showed that these phospholipid metabolites were independent predictors for the risk of a clinical vascular event.

If mechanistic links to any of these three lipid metabolites can be ascertained, this study offers new and exciting possibilities for therapeutic approaches to the prevention or treatment of atherosclerosis. Probiotic therapies have already been used to decrease TMAO levels, and the beneficial consequences of such modifications on atherogenesis are suggested by the study of Wang and colleagues (84).

\section{Prebiotics and Probiotics}

Humans live in symbiosis with a diverse community of microorganisms, the composition of which has evolved to carry out many specific tasks that benefit the host, as well as to survive and thrive in sites that provide these microorganisms with a suitable nutrient-filled habitat. These symbionts can be mutualists (benefiting themselves and the host), commensals (benefiting themselves but not the host) or pathogens (benefiting themselves by harming the host). The goal of identifying specific roles for these 100 trillion symbionts, the gene pool of which far exceeds that of their host, is currently elusive, but the composition of this microbiota is now being deciphered (148).

One rationale for the use of probiotics is to help restore and maintain homeostasis. Although the commercial field of probiotics is sadly still lined with too many undocumented products making unproven claims, the pending implementation by regulatory agencies of some or all of the guidelines published on what constitutes a probiotic will hopefully focus attention on those strains that have been proved to confer health benefits (149).

Prebiotics are short-chain carbohydrates that alter the composition, or metabolism, of the gut microbiota in a beneficial manner. It is therefore expected that prebiotics will improve health in a way similar to probiotics, whilst at the same time being cheaper, and carrying less risk and being easier to incorporate into the diet than probiotics (150).

Prebiotics are important because of: (i) the growing belief that there is such a thing as a healthy or balanced gut microbiota, (ii) the demonstration that prebiotics can alter the composition of the microbiota towards this more healthy profile, (iii) as an alternative to probiotics, which can be difficult to handle in some foodstuffs, but whose benefits to health in terms of diarrhea prevention and immunomodulation are becoming increasingly well established and (iv) because prebiotics currently in use, especially inulin and its derivatives, and galacto-oligosaccharides (GOS) are relatively cheap to manufacture or extract from plant sources, and in addition to having beneficial effects on the gut microbiota and host, they are also valuable functional ingredients in foods with the potential to give fat-based spreads and dairy products improved organoleptic properties (150). 'A prebiotic is a non-digestible food ingredient that beneficially affects the host by selectively stimulating the growth and/or activity of one of a limited number of bacteria in the colon, and thus improves host health' 
(151). Prebiotic supplementation was associated with an increase in plasma gut peptide concentrations (glucagonlike peptide 1 and peptide YY), which may contribute in part to changes in appetite sensation and glucose excursion responses after a meal in healthy subjects (152).

Obese and diabetic mice display enhanced intestinal permeability and metabolic endotoxaemia that participate in the occurrence of metabolic disorders. Recent data support the idea that a selective increase of Bifidobacterium spp. reduces the impact of high-fat diet-induced metabolic endotoxaemia and inflammatory disorders (137).

A selective gut microbiota change controls and increases endogenous GLP-2 production, and consequently improves gut barrier functions by a GLP-2dependent mechanism, contributing to the improvement of gut barrier functions during obesity and diabetes (137).

It is still early days for prebiotics, but evidence increasingly suggests that they offer the potential to modify the gut microbial balance in such a way as to bring direct health benefits cheaply and safely. A healthy, or 'balanced' microbiota has been considered to be one that is predominantly saccharolytic and comprises significant numbers of bifidobacteria and lactobacilli (153). This concept is based on a number of observations. The genera Bifidobacterium and Lactobacillus do not contain any known pathogens, and they are primarily carbohydratefermenting bacteria, unlike other groups, such as Bacteroides and clostridia which are also proteolytic and amino acid fermenting. The products of carbohydrate fermentation, principally short-chain fatty acids (SCFA) are beneficial to host health, while those of protein breakdown and amino acid fermentation, which include ammonia, phenols, indoles, thiols, amines and sulphides are not (154). Furthermore, lactic acid-producing bacteria, such as bifi-dobacteria and lactobacilli are believed to play a significant role in the maintenance of colonization resistance, through a variety of mechanisms (155).

Interest in the beneficial functions of the human microbiota has resulted in the selection of specific species with putative health-promoting capacities for the treatment of conditions in which the microbiota - or its optimal functioning - is disturbed. These microorganisms, recognized as probiotics (156), are generally selected from Lactobacillus or Bifidobacterium species (157).

Probiotics have been defined as "live microorganisms which when administered in adequate amounts confer a health benefit on the host" (158). The modes of action by which probiotics are thought to contribute to human health fall into three main categories (159). First, certain probiotics can exclude or inhibit pathogens. This is currently the best studied probiotic mechanism and has been exhaustively reviewed else where $(159,160)$. A second mechanism is to enhance the function of the intestinal epithelial barrier by modulating the various signalling pathways that lead to, for example, the induction of mucus (161) and defensin production $(162,163)$, enhancement of tight junction functioning (164) and prevention of apoptosis (165). The third method is to modulate host immune responses, resulting in both local and systemic effects (166). Although there is substantial evidence from in vitro and animal studies for each of these categories of probiotic action, the results from clinical studies are far less convincing (167). A better understanding of how probiotic bacteria interact with host cells is needed for their optimized application.

\section{Conclusion}

The human gut microbiota system may be regarded as a 'microbial organ' within the gut, which contributes to multiple host processes including the defense against pathogens at the gut level, immunity (mediated through a number of signal molecules and metabolites), the development of the intestinal microvilli, and the synthesis of several vitamins. Accumulating evidence indicates that the gut microbiota has a crucial role in conditions including obesity, diabetes, non-alcoholic fatty liver disease, inflammatory bowel disease (IBD) and even cancer.

Numerous animal models consistently demonstrated that gut microbiota can modulate host energy homeostasis and adiposity through different mechanisms, e.g., energy harvest from the diet,LPS- induced chronic inflammation, modulation of tissue fatty acid composition, and gutderived peptide secretion.

Toward this aim, it will be essential to elucidate the complex mechanisms of action of pre/probiotics, which are only lately being unraveled. While awaiting well designed RCTs with clinical end points, the importance of a "healthy" lifestyle in its broader sense-including breast lactation, a healthy diet, avoiding excessive fat, appropriate antibiotic use- cannot be overemphasized and may ensure a friendly gut microbiota, positively affecting metabolic outcomes. 


\section{References:}

1. Musso GS, Gambino R, Cassader M. Obesity, diabetes, and gut microbiota. Diab Care 2010; 33: 2277-84.

2. Hooper LV, Gordon JI. Commensal host-bacterial relationships in the gut. Science. 2001; 292: 1115-8.

3. Ley RE, Peterson DA, Gordon Jl. Ecological and evolutionary forces shaping microbial diversity in the human intestine. Cell. 2006; 124: 837-48

4. Neish AS. Microbes in gastrointestinal health and disease. Gastroenterology. 2009;136: 65-80

5. Blaser MJ, Falkow S. What are the consequences of the disappearing human microbiota? Nat Rev Microbiol. 2009; 7: 887-94.

6. Backhed F, Ding H, Wang T, Hooper LV, Koh GY, Nagy A, et al. The gut microbiota as an environmental factor that regulates fat storage. Proc Natl Acad Sci USA. 2004;101:1571815723.

7. Ley RE, Backhed F, Turnbaugh P, Lozupone CA, Knight RD, Gordon JI. Obesity alters gut microbial ecology. Proc Natl Acad Sci USA. 2005; 102: 11070-5.

8. Turnbaugh PJ, Ley RE, Hamady M, Fraser-Liggett CM, Knight $\mathrm{R}$, Gordon JI. The human microbiome project. Nature. 2007; 449: 804-10.

9. Turnbaugh PJ, Gordon JI. The core gut microbiome, energy balance and obesity. J Physiol. 2009; 587: 4153-8.

10. Turnbaugh PJ, Ley RE, Mahowald MA, Magrini V, Mardis ER, Gordon Jl. An obesity-associated gut microbiome with increased capacity for energy harvest. Nature. 2006; 444: 1027-31.

11. Diamant M, Blaak EE, de Vos M. Do nutrient - gut - microbiota interaction play a role in human obesity, insulin resistance and type 2 diabetes? Obes Rev 2011; 12 : 272-81.

12. Ley RE, Turnbaugh PJ, Klein S, Gordon JI. Microbial ecology: Human gut microbes associated with obesity. Nature 2006; 444: 1022-3.

13. Stappenbeck TS, Hooper LV, Gordon JI. Developmental regulation of intestinal angiogenesis by indigenous microbes via Paneth cells. Proc Natl Acad Sci USA 2002; 99: $15451-5$

14. Xu J, Gordon Jl. Inaugural article: Honor thy symbionts. Proc Natl Acad Sci USA 2003; 100: 10452-9.

15. HooperLV, Midtvedt T, Gordon JI. How host-microbial interactions shape the nutrient environment of the mammalian intestine. Annu Rev Nutr 2002; 22: 283-307.

16. MacDonald $\Pi$, Gordon JN. Bacterial regulation of intestinal immune responses. Gastroenterol Clin North Am 2005; 34 : 401-12.

17. Simpson S, Ash C, Pennisi E, Travis J. The gut inside out. Science 2005; 307: 1895 .

18. Zoetendal EG, Vaughan EE, ve Vos WM. A microbial world within us. Mol Microbiol 2006; 59: 1639-50.

19. Marchesi J, Shanahan F. The normal intestinal microbiota. Curr Opin Infect Dis 2007;20: 508-13.

20. Hooper LV, Bry L, Falk PG, Gordon JI. Host-microbial symbiosis in the mammalian intestine: exploring an internal ecosystem. Bioessays 1998; 20: 336-43.

21. Topping DL, Clifton PM. Short-chain fatty acids and human colonic function: roles of resistant starch and nonstarch polysaccharides. Physiol Rev 2001; 81:1031-64.

22. Bergman E. Energy contribution of volitile fatty acids from the gastrointestinal tract in various species. Physiol Rev 1990; 70: $567-90$

23. Wachtershauser A, Stein J. Rationale for the luminal provision of butyrate in intestinal diseases. Eur J Nutr 2000;3 9: 164-71.

24. Hamer HM, Jonkers D, Venema K, Vanhoutvin S, Troost FJ,
Brummer RJ. Review article: the role of butyrate on colonic function. Aliment Pharmacol Ther 2008; 27: 104-19.

25. Kumar A, Wu H, Collier-Hyams LS, Kwon YM, Hanson JM, Neish AS. The bacterial fermentation product butyrate influences epithelial signaling via ROS mediated changes in Cullin-1 neddylation. J Immunol. 2009; 182: 538-46.

26. Vernia P, Annese V, Bresci G, d'Albasio G, D'Incà R, Giaccari $S$, et al. Topical butyrate improves efficacy of 5-ASA in refractory distal ulcerative colitis: results of a multicentre trial. Eur J Clin Invest 2003;33:244-8.

27. Gueimonde M, Sakata S, Kalliomäki M, Isolauri E, Benno Y, Salminen S. Effect of maternal consumption of lactobacillus GG on transfer and establishment of fecal bifidobacterial microbiota in neonates. J Ped Gastroenterol Nutr 2006; 42:166-70

28. Vaishampayan PA, Kuehl JV, Froula JL, Morgan JL, Ochman H, Francino MP. Comparative metagenomics and population dynamics of the gut microbiota in mother and infant. Genome Biol Evol 2010; 2: 53-66.

29. Sela DA, Chapman J, Adeuya A, Kim JH, Chen F, Whitehead TR, et al. The genome sequence of Bifidobacterium longum subsp. infantis reveals adaptations for milk utilization within the infant microbiome. Proc Natl Acad Sci USA 2008; 105: 18964-9.

30. Palmer C, Bik EM, DiGiulio DB, Relman DA, Brown PO. Development of the human infant intestinal microbiota. PLoS Biol 2007; 5: e177.

31. Kurokawa $\mathrm{K}$, Itoh $\mathrm{T}$, Kuwahara $\mathrm{T}$, Oshima K, Toh H, Toyoda $\mathrm{A}$, et al. Comparative metagenomics revealed commonly enriched gene sets in human gut microbiomes. DNA Res 2007; 14: 169-81.

32. Dethlefsen L, Eckburg PB, Bik EM, Relman DA. Assembly of the human intestinal microbiota. Trends Ecol Evol 2006; 21: 517-23.

33. Koenig JE, Spor A, Scalfone N, Fricker AD, Stombaugh J, Knight $\mathrm{R}$, et al. Succession of microbial consortia in the developing infant gut microbiome. Proc Natl Acad Sci 2011; 108 (suppl. 1): 4578-

34. Gophna U. The guts of dietary habits. Science 2011; 334: 45-46.

35. Turnbaugh PJ, Ridaura VK, Faith JJ, Rey FE, Knight R, et al. The effect of diet on the human gut microbiome: a metagenomic analysis in humanized gnotobiotic mice. Sci Transl Med 2009;1: 6ra14.

36. Kovacs A, Ben-Jacob N, Tayem H, Halperin E, Iraqi FA, Gophna $U$. Genotype is a stronger determinant than sex of the mouse gut microbiota. Microb Ecol. 2011; 61: 423-8.

37. Wu GD, Chen J, Hoffmann C, Bittinger K, Chen YY, Keilbaugh $\mathrm{SA}$, et al. Linking long term dietary patterns with gut microbial enterotypes. Science 2011; 334: 105-8.

38. Faith JJ, McNutty NP, Rey FE, Gordon JI. Predicting a human gut microbiota's response to diet in gnotobiotic mice. Science 2011; 333: 101-4.

39. Johansson MEV, Hansson GC. Keeping bacteria at a distance. Science 2011; 334: 182-3.

40. Johansson ME, Phillipson M, Petersson J, Velcich A, Holm L, Hansson GC. The inner of the two Muc2 mucin-dependent mucus layers in colon is devoid of bacteria. Proc Natl Acad Sci USA. 2008; 10: 15064-9.

41. Macpherson AJ, McCoy KD, Johansen FE, Brandtzaeg P. The immune geography of $\lg \mathrm{A}$ induction and function. Mucosal Immunol 2008; 1:11-22

42. Hooper LV. Do symbiotic bacteria subvert host immunity? Nat Rev Microbiol 2009; 7: 367-74.

43. Boman HG. Innate immunity and the normal microflora. Immunol Rev 2000; 173: 5-16.

44. Dann SM, Eckmann L. Innate immune defenses in the intestinal tract. Curr Opin Gastroenterol 2007; 23:115-20. 
45. Turner JR. Intestinal mucosal barrier function in health and disease. Nat Rev Immunol 2009; 9:799-809.

46. Bäckhed F, Ley RE, Sonnenburg JL, Peterson DA, Gordon JI. Host-bacterial mutualism in the human intestine. Science 2005; 307:1915-1920.

47. McGuckin MA, Linden SK, Sutton P, Florin TH. Mucin dynamics and enteric pathogens. Nat Rev Microbiol 2011; 9: 265-78.

48. Johansson MEV, Larsson JMH, Hansson GC. The two mucus layers of colon are organized by the MUC2 mucin, the outer layer is a legislator of host - microbial interaction. Proc Natl Acad Sci USA 2011; 108 (suppl.1): 4659 - 65.

49. Stappenbeck TS. Paneth cell development, differentiation, and function: new molecular cues. Gastroenterology 2009; 137: 30-3.

50. Tomasetto C, Masson R, Linares JL, Wendling C, Lefebvre $\mathrm{O}$, Chenard MP, et al. pS2/TFF1 interacts directly with the WWFC cysteine-rich domains of mucins. Gastroenterology 2000; 118: 70-80.

51. Newton JL, Allen A, Westley BR, May FE. The human trefoil peptide, TFF1, is present in different molecular forms that are intimately associated with mucus in normal stomach. Gut 2000; 46: 312-20.

52. Ruchaud-Sparagano MH, Westley BR, May FE. The trefoil protein TFF1 is bound to MUC5AC in human gastric mucosa. Cell. Mol. Life Sci. 2004; 61: 1946-54.

53. Kindon H, Pothoulakis C, Thim L, Lynchdevaney G, Podolsky DK. Trefoil peptide protection of intestinal epithelial barrier function: cooperative interaction with mucin glycoprotein. Gastroenterology 1995; 109: 516-23.

54. Thim L, Madsen F, Poulsen SS.. Effect of trefoil factors on the viscoelastic properties of mucus gels. Eur. J. Clin. Invest. 2002; 32: 519-527.

55. Ouellette AJ. Paneth cells and innate mucosal immunity. Curr. Opin. Gastroenterol. 2010; 26: 547-53.

56. Porter EM, Bevins CL, Ghosh D, Ganz T. The multifaceted Paneth cell. Cell. Mol. Life Sci. 2002; 59: 156-70.

57. White SH, Wimley WC, Selsted ME. Structure, function, and membrane integration of defensins. Curr. Opin. Struct. Biol. 1995; 5, 521-7.

58. Hristova K, Selsted ME, White SH. Critical role of lipid composition in membrane permeabilization by rabbit neutrophil defensins. J. Biol. Chem. 1997; 272: 24224-33.

59. Bevin CL, Salzman NH. Paneth cels, antimicrobial peptides and maintenance of intestinal homeostasis. Nat Rev Microbiol 2011; 9: 356 - 68.

60. Salzman NH, Hung K, Haribhai D, Chu H, Karlsson-Sjöberg J, Amir E, et al. Enteric defensins are essential regulators of intestinal microbial ecology. Nature Immunol. 2010; 11: 7682.

61. Wilson CL, Ouellette AJ, Satchell DP, Ayabe T, López-Boado YS, Stratman JL, et al. Regulation of intestinal a-defensin activation by the metalloproteinase matrilysin in innate host defense. Science 1999; 286: 113-7.

62. Salzman NH, Ghosh D, Huttner KM, Paterson $\mathrm{Y}$, Bevins $\mathrm{CL}$. Protection against enteric salmonellosis in transgenic mice expressing a human intestinal defensin. Nature 2003; 422: 522.

63. Rioux JD, Xavier RJ, Taylor KD, Silverberg MS, Goyette P, Huett A, et al. Genome-wide association study identifies new susceptibility loci for Crohn disease and implicates autophagy in disease pathogenesis. Nature Genet. 2007; 39: 596-604.

64. Simms LA, Doecke JD, Roberts RL, Fowler EV, Zhao ZZ, McGuckin MA, et al. KCNN4 gene variant is associated with ileal Crohn's Disease in the Australian and New Zealand population. Am. J. Gastroenterol. 2010; 105: 2209-17.

65. Hugot JP, Chamaillard M, Zouali H, Lesage S, Cézard JP, Belaiche J, et al. Association of NOD2 leucine-rich repeat variants with susceptibility to Crohn's disease. Nature 2001; 411: 599-603.

66. Ogura Y, Bonen DK, Inohara N, Nicolae DL, Chen FF, Ramos $\mathrm{R}$, et al. A frameshift mutation in NOD2 associated with susceptibility to Crohn's disease. Nature 2001; 411: 603-6.

67. Wehkamp J, Wang G, Kübler I, Nuding S, Gregorieff A, Schnabel $A$, et al. The Paneth cell $\alpha$-defensin deficiency of ileal Crohn's disease is linked to Wnt/ Tcf-4. J. Immunol. 2007; 179: 3109-318.

68. Kaser A, Lee AH, Franke A, Glickman JN, Zeissig S, Tilg H, et al. XBP1 links ER stress to intestinal inflammation and confers genetic risk for human inflammatory bowel disease. Cell 2008; 134: 743-56.

69. Zheng W, Rosenstiel P, Huse K, Sina C, Valentonyte R, Mah N, et al. Evaluation of AGR2 and AGR3 as candidate genes for inflammatory bowel disease. Genes Immun. 2006; 7: 11-8.

70. Ayabe T, Wulff H, Darmoul D, Cahalan MD, Chandy KG, Ouellette AJ. Modulation of mouse Paneth cell $\alpha$-defensin secretion by mIKCa1, a $\mathrm{Ca} 2$ +-activated, intermediate conductance potassium channel. J. Biol. Chem. 2002; 277: 3793-800.

71. Kobayashi KS, Chamaillard M, Ogura Y, Henegariu O, Inohara $\mathrm{N}$, Nuñez G, et al. Nod2-dependent regulation of innate and adaptive immunity in the intestinal tract. Science 2005; 307 : $731-4$.

72. Biswas A, Liu YJ, Hao L, Mizoguchi A, Salzman NH, Bevins CL, et al. Induction and rescue of Nod2-dependent Th1-driven granulomatous inflammation of the ileum. Proc. Natl Acad. Sci. USA 2010; 107: 14739-44.

73. van Es JH, Jay P, Gregorieff A, van Gijn ME, Jonkheer S, Hatzis $\mathrm{P}$, et al. Wnt signaling induces maturation of Paneth cells in intestinal crypts. Nature Cell Biol. 2005; 7: 381-6.

74. Cadwell K, Liu JY, Brown SL, Miyoshi H, Loh J, Lennerz JK, et al. A key role for autophagy and the autophagy gene Atg16L1 in mouse and human intestinal Paneth cells. Nature 2008; 456: 259-63.

75. Cadwell K, Patel KK, Maloney NS, Liu TC, Ng AC, Storer CE. et al. Virus-plus-susceptibility gene interaction determines Crohn's disease gene Atg16L 1 phenotypes in intestine. Cell 2010; 141: 1135-45.

76. Vaishnava S, Yamamoto M, Severson KM, Ruhn KA, Yu X, Koren $\mathrm{O}$, et al. The antibacterial lectin Regll Igamma promotes the spatial segregation of microbiota and host in the intestine. Science 2011; 334: 255-8.

77. Lee YK, Mazmanian SK. Has the microbiota played a critical role in the evolution of the adaptive immune system? Science 2010; 330: 1768-73.

78. Maloy KJ, Powrie F. Intestinal Homeostasis and its breakdown in inflammatory bowel disease. Nature 2011; 474: 298- 306.

79. Artis D. Epithelial-cell recognition of commensal bacteria and maintenance of immune homeostasis in the gut. Nature Rev. Immunol. 2008; 8: 411-20.

80. Hooper LV, Macpherson AJ. Immune adaptations that maintain homeostasis with the intestinal microbiota. Nature Rev. Immunol. 2010; 10: 159-69.

81. Muegge BD, Kuczynski J, Knights D, Clemente JC, González A, Fontana $\mathrm{L}$, et al. Diet drives convergence in gut microbiome functions across mammalian phylogeny and within humans. Science 2011; 332: 970-4.

82. Goodman AL, Kallstrom G, Faith JJ, Reyes A, Moore A, Dantas $\mathrm{G}$, et al. Extensive personal human gut microbiota culture collections characterized and manipulated in gnotobiotic mice. Proc. Natl Acad. Sci. USA 2011; 108: 6252-7.

83. Turnbaugh PJ, Hamady M, Yatsunenko T, Cantarel BL, Duncan $\mathrm{A}$, Ley RE, et al. A core gut microbiome in obese and lean twins. Nature 2009; 457: 480-4.

84. Wikoff WR, Anfora AT, Liu J, Schultz PG, Lesley SA, Peters $E C$, et al. Metabolomics analysis reveals large effects of 
gut microflora on mammalian blood metabolites. Proc. Natl Acad. Sci. USA 2009; 106: 3698-703.

85. Martin FP, Wang Y, Sprenger N, Yap IK, Lundstedt T, Lek P, et al. Probiotic modulation of symbiotic gut microbial-host metabolic interactions in a humanized microbiome mouse model. Mol. Syst. Biol. 2008; 4: 157.

86. Kau AL, Ahern PP, Griffin NW, Goodman AL, Gordon Jl. Human nutrition, the gut microbiome and the immune system. Nature 2011; 474: 327-36.

87. Qin J, Li R, Raes J, Arumugam M, Burgdorf KS, Manichanh C, et al. A human gut microbial gene catalogue established by metagenomic sequencing. Nature 2010; 464: 59-65.

88. Lupton JR. Microbial degradation products influence colon cancer risk: the butyrate controversy. J. Nutr. 2004; 134: 479-82.

89. Bird JJ, Brown DR, Mullen AC, Moskowitz NH, Mahowald MA, Sider JR, et al. Helper T cell differentiation is controlled by the cell cycle. Immunity 1998; 9: 229-37.

90. Peng L, He Z, Chen W, Holzman IR, Lin J. Effects of butyrate on intestinal barrier function in a Caco- 2 cell monolayer model of intestinal barrier. Pediatr. Res. 2007; 61: 37-41.

91. Maslowski KM, Vieira AT, Ng A, Kranich J, Sierro F, Yu D, et al. Regulation of inflammatory responses by gut microbiota and chemoattractant receptor GPR43. Nature 2009; 461: 1282-6.

92. Nguyen MT, Favelyukis S, Nguyen AK, Reichart D, Scott PA, Jenn A, et al. A subpopulation of macrophages infiltrates hypertrophic adipose tissue and is activated by free fatty acids via Toll-like receptors 2 and 4 and JNK-dependent pathways. J. Biol. Chem. 2007; 282: 35279-92.

93. Mariathasan S, Weiss DS, Newton K, McBride J, O'Rourke K, Roose-Girma $\mathrm{M}$ et al. Cryopyrin activates the inflammasome in response to toxins and ATP. Nature 2006; 440: 228-32.

94. Thomson AW, Turnquist HR, Raimondi G. Immunoregulatory functions of mTOR inhibition. Nature Rev. Immunol. 2009; 9: 324-37.

95. Nakamura T, Furuhashi M, Li P, Cao H, Tuncman G, Sonenberg $\mathrm{N}$, et al. Double-stranded RNA-dependent protein kinase links pathogen sensing with stress and metabolic homeostasis. Cell 2010; 140: 338-48.

96. Stockinger B. Beyond toxicity: aryl hydrocarbon receptormediated functions in the immune system. J. Biol. 2009; 8: 61.

97. Glass CK, Ogawa S. Combinatorial roles of nuclear receptors in inflammation and immunity. Nature Rev. Immunol. 2006; 6: 44-55.

98. Esser C, Rannug A, Stockinger B. The aryl hydrocarbon receptor in immunity. Trends Immunol. 2009; 30: 447-54.

99. Mezrich JD, Fechner JH, Zhang X, Johnson BP, Burlingham WJ, Bradfield CA. An interaction between kynurenine and the aryl hydrocarbon receptor can generate regulatory $\mathrm{T}$ cells. J. Immunol. 2010; 185: 3190-8.

100. Platzer $B$, Richter $S$, Kneidinger $D$, Waltenberger $D$, Woisetschläger $M$, Strobl $H$. Aryl hydrocarbon receptor activation inhibits in vitro differentiation of human monocytes and Langerhans dendritic cells. J. Immunol. 2009; 183: 6674.

101. Quintana FJ, Basso AS, Iglesias AH, Korn T, Farez MF, Bettelli $\mathrm{E}$, et al. Control of Treg and TH17 cell differentiation by the aryl hydrocarbon receptor. Nature 2008; 453: 65-71.

102. Veldhoen M, Hirota K, Westendorf AM, Buer J, Dumoutier L, Renauld JC. et al. The aryl hydrocarbon receptor links TH17-cell-mediated autoimmunity to environmental toxins. Nature 2008; 453: 106-9.

103. Allen $\mathrm{RH}$, StablerSP. Identification and quantitation of cobalamin and cobalamin analogues in human feces. Am. J. Clin. Nutr. 2008; 87: 1324-35.

104. Goodman, A. L. et al. Identifying genetic determinants needed to establish a human gut symbiont in its habitat. Cell Host Microbe 2009; 6: 279-89.

105. Gill SR, Pop M, Deboy RT, Eckburg PB, Turnbaugh PJ, Samuel $\mathrm{BS}$, et al. Metagenomic analysis of the human distal gut microbiome. Science 2006; 312: 1355-9.

106. Sonnenburg JL, $\mathrm{Xu} \mathrm{J,} \mathrm{Leip} \mathrm{DD,} \mathrm{Chen} \mathrm{CH}$, Westover BP, Weatherford J, et al. Glycan foraging in vivo by an intestineadapted bacterialsymbiont. Science 2005; 307: 1955-9.

107. Preiss-Landl K, Zimmermann R, Hämmerle G, Zechner $\mathrm{R}$. Lipoprotein lipase: the regulation of tissue specific expression and its role in lipid and energy metabolism. Curr. Opin. Lipidol. 2002; 13: 471-81.

108. Bergö M, Olivecrona G, Olivecrona T. Forms of lipoprotein lipase in rat tissues: in adipose tissue the proportion of inactive lipase increases on fasting. Biochem. J. 1996; 313: 893-8.

109. Eckburg PB, Bik EM, Bernstein CN, Purdom E, Dethlefsen L, Sargent M, et al. Diversity of the human intestinal microbial flora. Science. 2005;308: 1635-8.

110.Andersson AF, Lindberg M, Jakobsson H, Backhed F, Nyren $P$, Engstrand L. Comparative analysis of human gut microbiota by barcoded pyrosequenc- ing. PLoS One. 2008; 3: e2836.

111.Dethlefsen L, Huse S, Sogin ML, Relman DA. The pervasive effects of an antibiotic on the human gut microbiota, as revealed by deep 16 S rRNA sequencing. PLoS Biol. 2008; 6: e280.

112.Fleissner CK, Huebel N, Abd El-Bary MM, Loh G, Klaus S, Blaut $M$. Absence of intestinal microbiota does not protect mice from diet-induced obesity. Br J Nutr. 2010; 104: 919-29.

113. Hildebrandt MA, Hoffmann C, Sherrill-Mix SA, Keilbaugh SA, Hamady $M$, Chen $Y Y$, et al. High fat diet determines the composition of the murine gut microbiome independently of obesity. Gastroenterology. 2009; 137: 1716-24.e1-2.

114.Tilg $\mathrm{H}$, kaser A. Gut microm=biome, obesity, and metabolic dysfunction. J Clin Invest 2011; 121: 2126-32.

115.Sonnenburg ED, Zheng H, Joglekar P, Higginbottom SK, Firbank SJ, Bolam DN, et al. Specificity of polysaccharide use in intestinal bacteroides species determines diet-induced microbiota alterations. Cell. 2010; 141: 1241-1252.

116. Hotamisligil GS, Erbay E. Nutrient sensing and inflammation in metabolic diseases. Nat Rev Immunol 2008; 8: 923-34.

117.Shoelson SE, Goldfine AB. Getting away from glucose: fanning the flames of obesity-induced inflammation. Nat Med 2009; 15: $373-4$.

118.Cani PD, Amar J, Iglesias MA, Poggi M, Knauf C, Bastelica D, et al. Metabolic endotoxemia initiates obesity and insulin resistance. Diabetes 2007; 56: 1761-72

119.Cani PD, Neyrinck AM, Fava F, Knauf C, Burcelin RG, Tuohy KM, et al. Selective increases of bifidobacteria in gut microflora improve high-fat-diet-induced diabetes in mice through a mechanism associated with endotoxaemia. Diabetologia 2007; 50: 2374-83.

120. Cani PD, Bibiloni R, Knauf C, Waget A, Neyrinck AM, Delzenne $\mathrm{NM}$, et al. Changes in gut microbiota control metabolic endotoxemia-induced inflammation in high-fat diet-induced obesity and diabetes in mice. Diabetes 2008; 57: 1470-81.

121. Cani PD, Delzenne NM. The role of the gut microbiota in energy metabolism and metabolic disease. Curr Pharm Des 2009; 15: $1546-58$

122. Lambert DM, Muccioli GG. Endocannabinoids and related $\mathrm{N}$-acylethanolamines in the control of appetite and energy metabolism: emergence of new molecular players. Curr Opin Clin Nutr Metab Care 2007; 10: 735-44.

123. Di Marzo V. Targeting the endocannabinoid system: to enhance or reduce? Nat Rev Drug Discov 2008; 7: 438-55.

124. Weisberg SP, McCann D, Desai M, Rosenbaum M, Leibel RL, Ferrante Jr AW. Obesity is associated with macrophage accumulation in adipose tissue. J Clin Invest 2003; 112: 1796-808. 
125. Muccioli GG, Naslain D, Backhed F, Reigstad C, Lambert DM, Delsenne $\mathrm{N}$, et al. The endocannabinoid system links gut microbiota to adipogenesis. Mol Syst Biol 2010; 6: 1- 15.

126. Alhamoruni A, Lee AC, Wright KL, Larvin M, O'Sullivan SE. Pharmacological effects of cannabinoids on the Caco-2 cell culture model of intestinal permeability. J Pharmacol Exp Ther. 2010; 335: 92-102.

127. Cani PD, Delzenne NM. Interplay between obesity and associated metabolic disorders: new insights into the gut microbiota. Curr Opin Pharmacol. 2009; 9: 737-43.

128. Tilg $\mathrm{H}$, Moschen AR. Adipocytokines: mediators linking adipose tissue, inflammation and immunity. Nat Rev Immunol. 2006; 6: $772-83$

129. Membrez M, Blancher F, Jaquet $M$, Bibiloni R, Cani PD, Burcelin $\mathrm{RG}$, et al. Gut microbiota modulation with norfloxacin and ampicillin enhances glucose tolerance in mice. FASEB J. 2008; 22: 2416-26.

130. Backhed F, Manchester JK, Semenkovich CF, Gordon JI. Mechanisms underlying the resistance to diet- induced obesity in germ-free mice. Proc Natl Acad Sci USA 2007; 104: 979-84.

131. Zhang $C$, Zhang M, Wang S, Han R, Cao Y, Hua W, et al. Interaction between gut microbiota, host genetics and diet relevant to development of metabolic syndromes in mice. ISME J 2010; 4: 232-41.

132. Vijay-Kumar M, Aitken JD, Carvalho FA, Cullender TC, Mwang $\mathrm{S}$, Srinivasan S, et al. Metabolic syndrome and altered gut microbiota in mice lacking Toll-like receptor 5 . Science. 2010; 328: 228-31.

133. Garrett WS, Lord GM, Punit S, Lugo-Villarino G, Mazmanian $\mathrm{SK}$, Ito $\mathrm{S}$, et al. Communicable ulcerative colitis induced by T-bet deficiency in the innate immune system. Cell. 2007; 131: 33-45.

134. De Kort S, Keszthelyi D, Masclee AM. Leaky gut and diabetes mellitus: what is the link? Obes Rev 2011; 12: 449-58.

135. Arrieta MC, Bistritz L, Meddings JB. Alterations in intestinal permeability. Gut 2006; 55: 1512-20.

136. Anderson JM, Van Itallie CM. Physiology and function of the tight junction. Cold Spring Harb Perspect Biol 2009; 1: a002584.

137. Tiittanen M, Paronen J, Savilahti E, Virtanen SM, Ilonen J, Knip $\mathrm{M}$, et al. Dietary insulin as an immunogen and tolerogen. Pediatr Allergy Immunol 2006; 17: 538-43.

138. Cani PD, Possemiers $S$, Van de Wiele T, Guiot $Y$, Everard $\mathrm{A}$, Rottier $\mathrm{O}$, et al. Changes in gut microbiota control inflammation in obese mice through a mechanism involving GLP- 2-driven improvement of gut permeability. Gut 2009; 58: 1091-103.

139. Loscalzo J. Lipid metabolism by gut microbes and atherosclerosis. Circ Res 2011; 109: 127-9.

140. Goodman AL, Gordon JI. Our unindicted coconspirators: human metabolism from a microbial perspective. Cell Metab. 2010;12:111-2.

141. Dumas ME, Barton RH, Toye A, Cloarec O, Blancher C, Rothwell $\mathrm{A}$, et al. Metabolic profiling reveals a contribution of gut microbiota to fatty liver phenotype in insulin-resistant mice. Proc Natl Acad Sci USA. 2006; 103: 12511-6.

142. Savage DC. Microbial ecology of the gastrointestinal tract. Annu Rev Microbiol. 1977; 31: 107-33.

143. Arumugam M, Raes J, Pelletier E, Le Paslier D, Yamada T, Mende DR, et al. Enterotypes of the human gut microbiome. Nature. 2011; 73: 174-80

144. Velagapudi VR, Hezaveh R, Reigstad CS, Gopalacharyulu P, Yetukuri L, Islam S, e al. The gut microbiota modulates host energy and lipid metabolism in mice. J Lipid Res. 2010; 51 1101-12.

145. Backhed F, Crawford PA. Coordinated regulation of the metabolome and lipidome at the host-microbial interface. Biochim Biophys Acta. 2010; 1801:240 -5.
146. Wang Z, Klipfell E, Bennett BJ, Koeth R, Levison BS, Dugar B, et al. Gut flora metabolism of phosphatidylcholine promotes cardiovascular disease. Nature. 2011; 472: 57-63.

147. Rak K, Rader DJ. The diet - microbe morbid union. Nature 2011; 472: $40-1$

148. Zeisel SH, Mar MH, Howe JC, Holden JM. Concentrations of choline-containing compounds and betaine in common foods. Nature 2003; 133: 1302 - 7.

149. Reid G, Younes JA, van der Mei H, Gloor GB, Knight R, Busscher HJ. Microbiota restoration: natural and supplemented recovery of human microbial communities. Nat Rev Microbiol 2011; 9: 27-38.

150. Reid, G. The importance of guidelines in the development and application of probiotics. Curr. Pharm. Des. 2005; 11: 11-6.

151. Macfarlane S, Macfarlane GT, Cummings JH. Review article: prebiotics in the gastrointestinal tract. Aliment Pharmacol Ther 2006; 24: 701-14.

152. Gibson GR, Roberfroid M. Dietary modulation of the human colonic microbiota: introducing the concept of prebiotics. J Nutr 1995; 125: 1401-12.

153. Cani PD, Lecourt E, Dewulf E, Sohet FM, Pachikian BD, Naslain $D$, et al. Gut microbiota fermentation of prebiotics increases satietogenic and incretin gut production woth consequences for appetite sensation and glucose response after a meal. Am J Clin Nutr 2009; 90: 1236- 43.

154. Cummings JH, Antoine JM, Azpiroz F, Bourdet-Sicard R, Brandtzaeg $\mathrm{P}$, Calder $\mathrm{PC}$, et al. Gut health and immunity. Eur J Nutr 2004; 43: II/118-73.

155. Cummings JH, Macfarlane GT. The control and consequences of bacterial fer- mentation in the human colon. J Appl Bacteriol 1991; 70: 443-59.

156. Gibson GR, McCartney AL, Rastall RA. Prebiotics and resistance to gastrointes- tinal infections. Br J Nutr 2005; 93: S31-4.

157. Food and Agriculture Organization of the United Nations and WHO. Health and nutritional properties of probiotics in food including powder milk with live lactic acid bacteria. (FAO, Rome/WHO, Geneva, 2001).

158. Marco, M. L., Pavan, S. \& Kleerebezem, M. Towards understanding molecular modes of probiotic action. Curr. Opin. Biotechnol. 2006; 17: 204-10.

159. Salminen S, Bouley C, Boutron-Ruault MC, Cummings $J H_{\text {, }}$ Franck A, Gibson GR, et al. Functional food science and gastrointestinal physiology and function. Br J Nutr 1998; 80(Suppl 1): 147-71.

160. Lebeer, S, Vanderleyden J, De Keersmaecker S. Genes and molecules of Lactobacillus supporting probiotic action. Microbiol. Mol. Biol. Rev. 2008; 72: 728-64.

161. Servin AL. Antagonistic activities of lactobacilli and bifidobacteria against microbial pathogens. FEMS Microbiol. Rev. 2004; 28: 405-

162. Mack DR, Ahrne S, Hyde L, Wei S, Hollingsworth MA. Extracellular MUC3 mucin secretion follows adherence of Lactobacillus strains to intestinal epithelial cells in vitro. Gut 2003; 52: 827-33.

163. Schlee M, Harder J, Köten B, Stange EF, Wehkamp J, Fellermann K. Probiotic lactobacilli and VSL\#3 induce enterocyte $\beta$-defensin 2. Clin. Exp. Immunol. 2008; 151: 528-35

164. Schlee M, Wehkamp J, Altenhoefer A, Oelschlaeger TA, Stange $E F$, Fellermann K. Induction of human $\beta$-defensin 2 by the probiotic Escherichia coli Nissle 1917 is mediated through flagellin. Infect. Immun. 2007; 75: 2399-407.

165. Seth A, Yan F, Polk DB, Rao RK. Probiotics ameliorate the hydrogen peroxide-induced epithelial barrier disruption by a PKC- and MAP kinase- dependent mechanism. Am. J. Physiol. Gastrointest. Liver Physiol. 2008; 294: G1060-9.

166. Yan, F. et al. Soluble proteins produced by probiotic bacteria regulate intestinal epithelial cell survival and growth. Gastroenterology 2007; 132: 562-75. 
167. Smits HH, Engering A, van der Kleij D, de Jong EC, Schipper $\mathrm{K}$, van Capel TM, et al. Selective probiotic bacteria induce IL-10-producing regulatory $\mathrm{T}$ cells in vitro by modulating dendritic cell function through dendritic cell-specific intercellular adhesion molecule 3-grabbing nonintegrin. J. Allergy Clin. Immunol. 2005; 115: 1260-7.
168. Goldin BR, Gorbach SL. Clinical indications for probiotics: an overview. Clin. Infect. Dis. 2008; 46: S96-100. 